\title{
Using Graphene Encapsulated Ni and Pd Catalysts with Solvent Effect to Achieve Highly Chemo-Selective Hydrogenation of 4-Nitrostyrene to Different Products
}

\author{
Jianguo Liu ${ }^{1,2,3^{*}}$, Jiangmin $\mathrm{Sun}^{2}$, Shanshan $\mathrm{Lin}^{2}$, Longlong Ma ${ }^{1,2 *}$ \\ ${ }^{1}$ Key Laboratory of Energy Thermal Conversion and Control of Ministry of Education, School of Energy and \\ Environment, Southeast University, Nanjing 210096, PR China. \\ ${ }^{2}$ CAS Key Laboratory of Renewable Energy, Guangdong Provincial Key Laboratory of New and Renewable \\ Energy Research and Development, Guangzhou Institute of Energy Conversion, Chinese Academy of Sciences, \\ Guangzhou 510640, P. R. China. \\ ${ }^{3}$ Dalian National Laboratory for Clean Energy, Chinese Academy of Sciences, Dalian 116023, P. R. China. \\ * Corresponding authors e-mail: liujg@ms.giec.ac.cn; mall@ms.giec.ac.cn \\ \# These authors contributed equally to this work.
}

\begin{abstract}
Chemo-selective hydrogenation of challenging nitrostyrene to the corresponding product of vinylaniline, ethylbenzenamine, and ethylnitrobenzene separately in high yield is difficult since there exists competitive activation of the $\mathrm{C}=\mathrm{C}$ double bond and the $-\mathrm{NO}_{2}$ group over most supported metal catalysts. Also, the currently reported catalysts still have some disadvantages of high cost, catalyst reusability and separation problem, catalyst stability and leaching during harsh reaction conditions, waste generation, which disagree with the requirements of low cost, highly active and selective, sustainable, environmentally friendlier, and industrially applicable. Herein we report thin graphene layer encapsulated $\mathrm{Ni}$ and $\mathrm{Pd}$ nanoparticles core-shell structures as highly active, chemo-selective, and reusable catalysts for hydrogenation of 4-nitrostyrene in both batch reactor and industrially applicable flow reactor. In the standard hydrogenation of 4-nitrostyrene, the optimized catalysts $\mathrm{Ni} / \mathrm{NiO} @-700-200-1-\mathrm{H}_{2} \mathrm{O}$ and $\mathrm{Pd} @ \mathrm{NC}-2$ yield a selectivity to every single product of 4-vinylaniline $99 \%$, 4-ethylbenzenamine $99 \%$, 1-ethyl-4-nitrobenzene $99 \%$ through simple changing reaction conditions, the best achieved over $\mathrm{Ni}$ and other group metals and higher than the best result reported in the literature. In non-polar solvent toluene, in contrast to traditional catalysts, the $\mathrm{Ni} @ \mathrm{C}$ catalyst is inert for the $\mathrm{C}=\mathrm{C}$ and is only active about the $-\mathrm{NO}_{2}$, while the $\mathrm{N}$-doped Pd@NC-2 has opposite hydrogenation ability and can hydrogenate the $\mathrm{C}=\mathrm{C}$ without touching $-\mathrm{NO}_{2}$ in non-polar solvent cyclohexane, which rarely reported in the previous literature. In addition, the catalysts show excellent stability and the 4-nitrostyrene's hydrogenation can be successfully applied in industrially applicable flow reactors for each of the three product syntheses separately with excellent yield. These discoveries may extend the design of non-noble catalysts with excellent chemoselectivity for use in fine chemicals' synthesis.
\end{abstract}

\section{KEY WORD}

Nitrostyrene; chemo-selective hydrogenation; Ni@graphene catalyst; N-doped Pd@graphene catalysts; flow reactor

\section{INTRODUCTION}

Amines with various functional groups such as unsaturated bonds $\mathrm{C}=\mathrm{C}, \mathrm{C}=\mathrm{O}, \mathrm{C} \equiv \mathrm{C}$, and $\mathrm{C} \equiv \mathrm{N}$, are classified as privileged compounds and are widely used in fine chemicals, herbicides, pharmaceuticals, dyestuffs, agrochemicals, dyes, and polymers ${ }^{1-6}$. Specifically, there are more than 110 amine derivatives drugs containing nitrogen and/or amino groups in the reported top 200 pharmaceuticals by Retail Sales in $2020^{7}$. With the serious problems raised from the environmental and economic, especially the recent widespread COVID-19 problems, the development of fast, efficient, and environmentally friendlier synthesis processes for amines derivatives are urgent ${ }^{8-10}$. So far, many synthetic methodologies have been developed and applied in academics and industry $^{3,4,11-15}$. One of the important and popular chemical transformations is using supported 
noble-metal-based catalysts for the chemo-selective hydrogenation reactions of aromatic functionalized nitroarenes. Here, it is necessary to talk about the challenges and difficulties in the functionalized nitroarenes' selective hydrogenation. Generally, it is easy to hydrogenate a simple molecule with one functional group such as nitrobenzene into the desired product (amines) using a certain metal catalyst like $\mathrm{Pd} / \mathrm{C}$. But in the hydrogenation of functionalized nitroarenes, especially for the two of most challenging candidates 4-nitrostyrene and 3-nitrostyrene, the key issue for the selective synthesis of the targeted 4-vinylaniline (4-VA) or 3-vinylaniline (3-VA) is to discriminatively activate the nitro group and leave the $\mathrm{C}=\mathrm{C}$ bond intact. However, since both the Ar- $\mathrm{NO}_{2}$ and $\mathrm{C}=\mathrm{C}$ double bond can be simultaneously activated and easily hydrogenated, it is very difficult to achieve a high selective reduction of $\mathrm{Ar}-\mathrm{NO}_{2}$ without affecting other reducible groups under the catalytic conditions ${ }^{16-20}$. There are some generally findings during the past few years: 1 ) It is thermodynamically easier to hydrogenate unsaturated bonds like $\mathrm{C}=\mathrm{C}$ than the $\mathrm{NO}_{2}$ group ${ }^{21}$; 2) The nucleophilic sites on the catalyst prefer the adsorption of $\mathrm{NO}_{2}$ group while repel the $\mathrm{C}=\mathrm{C}$ bonds, due to the different electronic property of electron-rich $\mathrm{C}=\mathrm{C}$ bonds and electron-deficient $\mathrm{NO}_{2}$ groups ${ }^{22,23}$; 3) The sensitive hydrogenation of double $\mathrm{C}=\mathrm{C}$ bond to the catalyst structure instead of the $-\mathrm{NO}_{2}$ functional group. ${ }^{24}$

Following on from the above-mentioned findings, the noble metal catalysts like $\mathrm{Ru}, \mathrm{Pd}, \mathrm{Pt}$, and Au usually have high hydrogenation ability and they were predominant traditionally and had been studied widely for achieving selective reduction a long time. In 2006, Corma and Serna first reported the Au-based catalysts in the reduction of 3-nitrostyrene, ${ }^{16}$ excellent reactivity $(98.5 \%$ con.) and selectivity (95.9\%) were obtained using the $\mathrm{Au} / \mathrm{TiO}_{2}$ catalysts. Since then, many researchers have developed efficient noble metal-based catalysts for the chemo-selective hydrogenation of 3(4)-vinylaniline. Recently, Song et.al synthesized Au-melamine colloidal spheres by directly heating an aqueous solution of $\mathrm{Au}^{3+}$ and melamine at $70{ }^{\circ} \mathrm{C}{ }^{25}$. Then in the mixed solution containing colloidal sphere and poly(sodium-p-styrenesulfonate)(PTS), they rapidly added a great amount of $\mathrm{NaBH}_{4}$ and obtained multi-shell Au with modification of reducing PTS in situ. The prepared surface-modified with more shell number catalyst S-PTSAu displayed excellent reactivity (>99\%) and selectivity $(97 \%)$ in the $\mathrm{NH}_{3} \cdot \mathrm{BH}_{3}$ initiated selective hydrogenation of 4-nitrostyrene under light condition (Xe lamp at $0.5 \mathrm{Wcm}^{-2}$ with $420 \mathrm{~nm}$ cutoff filter at $25{ }^{\circ} \mathrm{C}$ ), compared with unmodified Au and other Au catalysts with less shell number. While in this reaction, like many other selective reduction processes in the industry, a large amount of reducing agents such as 2.5 equiv. $\mathrm{NH}_{3} \cdot \mathrm{BH}_{3}$ in this case, sodium hydrosulphite ${ }^{26}$, samarium iodide ${ }^{27}$, stannous chloride ${ }^{28}$ is still typically used, and it normally generate huge amounts of waste. Compared with other reducing agents or other hydrogen donors, molecular $\mathrm{H}_{2}$ is cheaper, readily available, and also environmentally benign. With the use of molecular $\mathrm{H}_{2}$, Zhang et. al. reported a rationally designed highly active and chemo-selective $\mathrm{FeO}_{\mathrm{x}}$-supported $\mathrm{Pt}$ catalyst for hydrogenation of substituted nitroarenes ${ }^{29}$. They also found that the hydrogenation of other unsaturated functional groups was unavoidable when the reaction time was prolonged and/or the temperature was raised. Later, using a ZnAl-hydrotalcite supported thiolated Au nanoclusters as a precatalyst, they obtained the well-tuned sized Au nanocatalysts that were only highly active for the $-\mathrm{NO}_{2}$ group but inert with respect to the $\mathrm{C}=\mathrm{C}$ bond, resulting in the excellent reactivity ( $100 \%$ con.) and outstanding selectivity (>98\%) of 3-VA in wide reaction period and temperature windows ${ }^{30}$. Recently, the Hutchings group ${ }^{31}$ described a synthesis method of a low metal loading $\mathrm{Pt} / \mathrm{TiO}_{2}$ catalyst through careful manipulation of the post-synthetic heat treatment procedure including calcination and subsequent reduction, together with control over the metal loading, thereby preventing any $\mathrm{TiOx}$ coverage of the $\mathrm{Pt}$ active sites. The prepared $\mathrm{Pt} / \mathrm{TiO}_{2}$ catalyst showed $99 \%$ conversion and $90 \%$ 3-VA selectivity in the hydrogenation of 3-nitrostyrene. Although there exist many advanced efficient noble metal-based catalysts for chemo-selective hydrogenation, the current trend in the pharmaceutical and agrochemical industries is the advancement of economical, green, and environmentally friendlier processes. Since the high cost and scarcity of noble metal, it is important and highly desirable to develop more cost-effective and practical application methodologies ${ }^{31,32}$.

In the meantime, the development of non-noble metal heterogeneous catalysts has attracted much attention, due to their obvious advantages of low cost, comparable reactivity, practical 
separation, and recyclability ${ }^{16,33-47}$. Specifically, the non-noble heterogeneous catalysts (like $\mathrm{Fe}_{2} \mathrm{O}_{3}$-based, $\mathrm{Ni} / \mathrm{TiO}_{2}, \mathrm{Co}_{3} \mathrm{O}_{4}$-based catalysts mainly $\mathrm{Fe}, \mathrm{Co}, \mathrm{Ni}$ ) using hydrogen sources have shown great potential in the hydrogenation of nitro compounds for the preparation of amines ${ }^{48-53}$. Beller and his co-workers first reported a nitrogen-doped carbon layer encapsulated active $\mathrm{Fe}_{2} \mathrm{O}_{3}$ particles based catalyst, and they applied it in the hydrogenation of nitroarenes including the 3 -nitrostyrene with $93 \%$ selectivity of $\mathbf{3}$-VA under a comparably mild conditions $\left(120{ }^{\circ} \mathrm{C}, 50\right.$ bar $\left.\mathrm{H}_{2}, 16 \mathrm{~h}\right){ }^{37}$. This group also developed the conversion of a homogeneous cobalt-phenanthroline (ligand) complex into heterogeneous cobalt oxide catalysts via immobilization on activated commercially available carbon and sub-sequent pyrolysis process. The amine ligands can not only affect cobalt particles on the carbon-nitrogen surface but also indirectly control the catalyst's activity and product's selectivity. The resulting $\mathrm{N}$-doped $\mathrm{Co}_{3} \mathrm{O}_{4}$-based catalyst gave $91 \%$ 3-VA selectivity under slightly mild reaction conditions $\left(120^{\circ} \mathrm{C}, 50 \mathrm{bar} \mathrm{H}_{2}, 6 \mathrm{~h}\right)^{54}$. Later, Corma and his co-workers prepared non-N-doped monodispersed Co nanoparticles covered with thin carbon layers (Co@C) by thermal decomposition of a Co-EDTA complex. The carbon layers can protect the metallic Co from over-oxidation by air. Using the Co@C nanoparticles catalyst, 95\% conversion of 3-nitrostyrene and 93\% 3-VA selectivity were obtained under the conditions of 7 bar of $\mathrm{H}_{2}, 120{ }^{\circ} \mathrm{C}{ }^{55}$. Recently, this group showed the synthesis of nano layered molybdenum disulfide cobalt-promoted materials (Co-Mo-S) via a one-pot hydrothermal synthesis ${ }^{56}$. The optimized unsupported catalyst Co-Mo-S-0.39-180, which has a large number of active sites per unit volume, gave $99 \%$ reactivity and $91 \%$ 3-VA selectivity under optimized reaction condition $\left(150{ }^{\circ} \mathrm{C}, 11 \mathrm{bar}\right.$ $\mathrm{H}_{2}, 7 \mathrm{~h}$, Toluene). In the catalyst's stability test of 7 runs, the catalytic activity and product yield gradually dropped from $99 \%$ to $75 \%$ and $99 \%$ to $68 \%$ respectively. For the first time, this group also synthesized the $\mathrm{Ni}$ catalysts via yielding nano sized crystals of the metals on the surface of $\mathrm{TiO}_{2}$ support and embedding the exposed (111) and (100) crystal faces using a simple procedure for catalyst activation. The resulting $\mathrm{Ni} / \mathrm{TiO}_{2}$ catalyst could change the relative rate for hydrogenating competitive groups present in the molecule by almost 2 orders of magnitude and showed $90 \%$ 3-VA selectivity, $93 \%$ conversion under fairly harsh reaction conditions $\left(450{ }^{\circ} \mathrm{C}, 15\right.$ bar $\mathrm{H}_{2}, \mathrm{x}$ h, solvent ${ }^{57}$. Here it also needs to specifically mention, also using other hydrogen donor ammonia borane like previously Song's reported S-PTSAu catalyst system ${ }^{25}$, Sun and his co-workers ${ }^{58}$ recently report the novel synthesis method of a highly efficient $\mathrm{Cu} / \mathrm{WO}_{2.72}$ catalyst for chemo-selective hydrogenation of 3-nitrostyrene. By controlling catalytic activity and selectivity of $\mathrm{Cu}$ nanoparticles (NPs) through anchoring on $\mathrm{WO}_{2.72}$ nanorods, the $\mathrm{Cu} / \mathrm{WO}_{2.72}$ catalyst showed $>99 \%$ yield of $\mathbf{3 - V A}$ under mild reaction conditions $\left(25^{\circ} \mathrm{C}, 3\right.$ equiv. $\mathrm{NH}_{3} \cdot \mathrm{BH}_{3}$, $\mathrm{EtOH}, 1.5 \mathrm{~h}$ ). Due to the strong interfacial interaction between $\mathrm{Cu}$ NPs and $\mathrm{WO}_{2.72}$, the $\mathrm{WO}_{2.72}$ could activate and stabilize $\mathrm{Cu}$ NPs. And the $\mathrm{Cu} / \mathrm{WO}_{2.72}$ catalyst maintained its initial activity and selectivity even after six catalytic cycles.

Despite the great progress that has been made in noble and non-noble heterogeneous catalysts for the chemo selective hydrogenation of challenging substrates 4-nitrostyrene or 3-nitrostyrene, some of the currently developed catalysts are still facing the relatively high cost, inevitably lost during the recovery process, relative harsh reaction conditions, recycling and separation difficulties, waste generation especially when using high equivalent of other hydrogen sources $\left(\mathrm{NH}_{3} \cdot \mathrm{BH}_{3}, \mathrm{NaBH}_{4}\right)$, and the problem of being able to be industrialized and practically applied. But at the same time, with the dramatically increasing demand for amine synthesis, especially the requirements for sustainable environmental and economic performance in recent years, low cost, sustainable, high active, and industrial applicable heterogeneous catalysts are remained to be developed urgently. In addition, in the abovementioned catalysts for hydrogenation 4-nitrostyrene or 3-nitrostyrene, we can get vinyl-benzenamine, or the second product of ethyl-benzenamine with modification of catalyst ${ }^{58}$, however, it is usually more difficult to obtain the high chemo-selective products ethylnitrobenzene and vinyl-benzenamine separately in high yield. So, in this case, whether can we developed the most idealist hydrogenation of 4-nitrostyrene system, in which every single product of 4-VA, 4-ethylbenzenamine (4-EA), and 1-ethyl-4-nitrobenzene (4-ENB) can be obtained selectively and in high yield by changing the process conditions? Undoubtedly, this idealist hydrogenation of the 4-nitrostyrene system, is a very critical, important, and novel breakthrough in the application of chemical synthesis and industrial. 
Herein, we would like to report this idealist hydrogenation of 4-nitrostyrene system using thin graphene layer encapsulated $\mathrm{Ni@graphene} \mathrm{and} \mathrm{Pd@graphene} \mathrm{catalyst} \mathrm{in} \mathrm{both} \mathrm{batch} \mathrm{reactor} \mathrm{and}$ industrially applicable flow reactor. Graphene, which has been recognized as one of the hardest, thinnest, thermal and electrical conductivity materials, especially for its recent discovered superconductivity and correlated insulating phases in the magic-angle twisted bilayer, three-layer graphene, ${ }^{59-62}$ 63-65 was successfully prepared via situ facile synthesis method with a thin layer as the "bulletproof vests" for active metal species in this work. The prepared Ni@graphene and Pd@graphene catalysts having the graphene "bulletproof vests" which enhance the anti-interference ability and stability of the active metal components, showed excellent activity (99\%) and selectivity (99\%) in the chemo selective hydrogenation of the 4-nitrostyrene system. Moreover, by optimizing the reaction conditions, three types of desired products 4-VA, 4-EA, and 4-ENB could be obtained with over $99 \%$ yield respectively, which was not mentioned during the previous report. In addition, the highly chemo-selective hydrogenation of 4-nitrostyrene can be carried out in the industrially applicable flow reactor, and catalysts can be easily separated from the product because of its magnetic properties or flow reactor systems and showed excellent stability during the reaction.

\section{RESULTS AND DISCUSSION.}

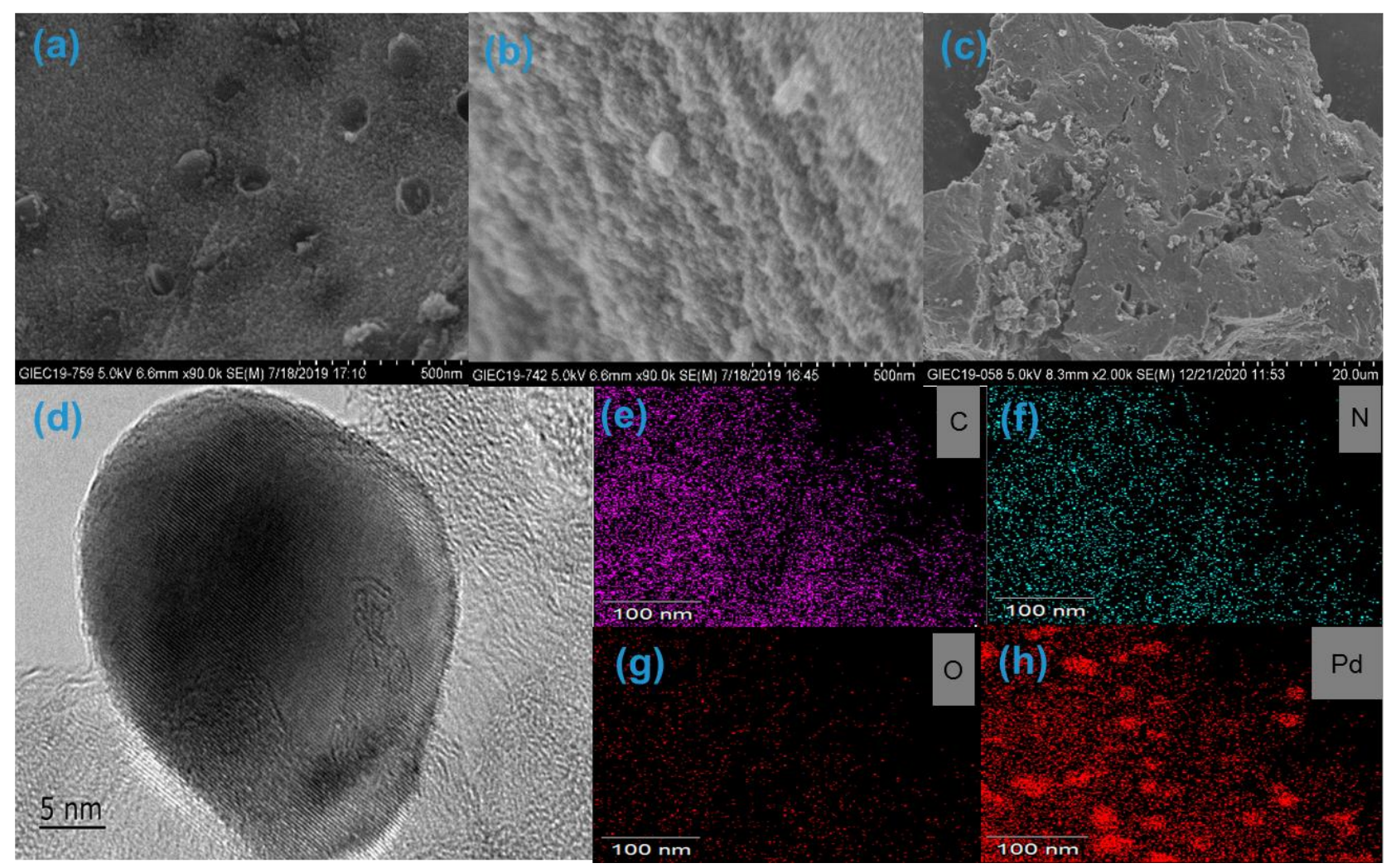

Figure 1. Representative SEM images of $\mathrm{Ni} @ \mathrm{C}-700-200-1 \mathrm{~h}-\mathrm{H}_{2} \mathrm{O}$ (a), Ni@C-700- $\mathrm{H}_{2} \mathrm{O}$ (b), Pd@NC-2 (c) ; Representative HAADF-TEM image of Pd@NC-2 (d) and corresponding EDS element mapping (EFTEM) of C, N, O and Pd (e-h).

The Ni@graphene and Pd@graphene catalysts were synthesized with the modified facile synthesis method (Scheme S1). All these prepared catalysts were numbers as $\mathrm{M}_{1} / \mathrm{M}_{2} @(\mathrm{~N}) \mathrm{C}-\mathrm{a}-\mathrm{b}-\mathrm{c}-\mathrm{d}$, where $\mathrm{M}_{1}=\mathrm{Ni}, \mathrm{Pd} ; \mathrm{M}_{2}=\mathrm{NiO}, \mathrm{PdO} ; \mathrm{a}$ is pyrolysis temperature; $\mathrm{b}$ is oxidation temperature; $\mathrm{c}$ is oxidation time, and $\mathrm{d}$ is solvent. Figure 1 showed some representative scanning electron microscopy (SEM) images and high-angle annular dark-field-STEM (HAADF-STEM) images of oxidized and non-oxidized samples of graphene encapsulated $\mathrm{Ni@C}$ catalysts, and nitrogen-doped graphene encapsulated Pd@NC catalyst. The other catalysts' corresponding images are presented in Supplementary Information. As illustrated in Figure $\mathbf{1 a}$ and $\mathbf{1 b}$, the oxidized catalyst $\mathrm{Ni} @ \mathrm{C}-700-200-1 \mathrm{~h}-\mathrm{H}_{2} \mathrm{O}$ has the obvious pores structure on the catalyst surface. Also, the solvent and pyrolysis temperature can affect the catalyst's surface significantly ${ }^{31}$. The $\mathrm{Ni} @ \mathrm{C}$ catalysts 
prepared with $\mathrm{H}_{2} \mathrm{O}$ have bigger catalyst particles compared with the catalysts prepared with EtOH (Figure S1). According to the SEM-EDS element analysis, the oxidized Ni@C catalysts have a higher metal loading of $\mathrm{Ni}$, lower loading of $\mathrm{C}$, and $\mathrm{O}$, compared with the un-oxidized catalysts (Table S1). According to the HR-TEM analysis, the prepared Ni@C and N-doping Pd@NC-2 catalysts consisted of metal nanoparticles that were encapsulated by less than 5 graphene layers (Figure 1d, Figure S1), and $>90 \%$ of metal species were encapsulated by a few graphene layers 55,66-68. As shown in the corresponding energy-dispersive X-ray (EDX) images, the $\mathrm{C}, \mathrm{N}$, and $\mathrm{O}$ atoms were dispersed homogeneously over all the Pd NPs (Figure 1e-h), and this confirmed that the Pd@NC-2 catalyst has the alloy structure. The C, O, and $\mathrm{Ni}$ atoms were also distributed homogeneously over the prepared Ni@C catalysts (Figure S1).

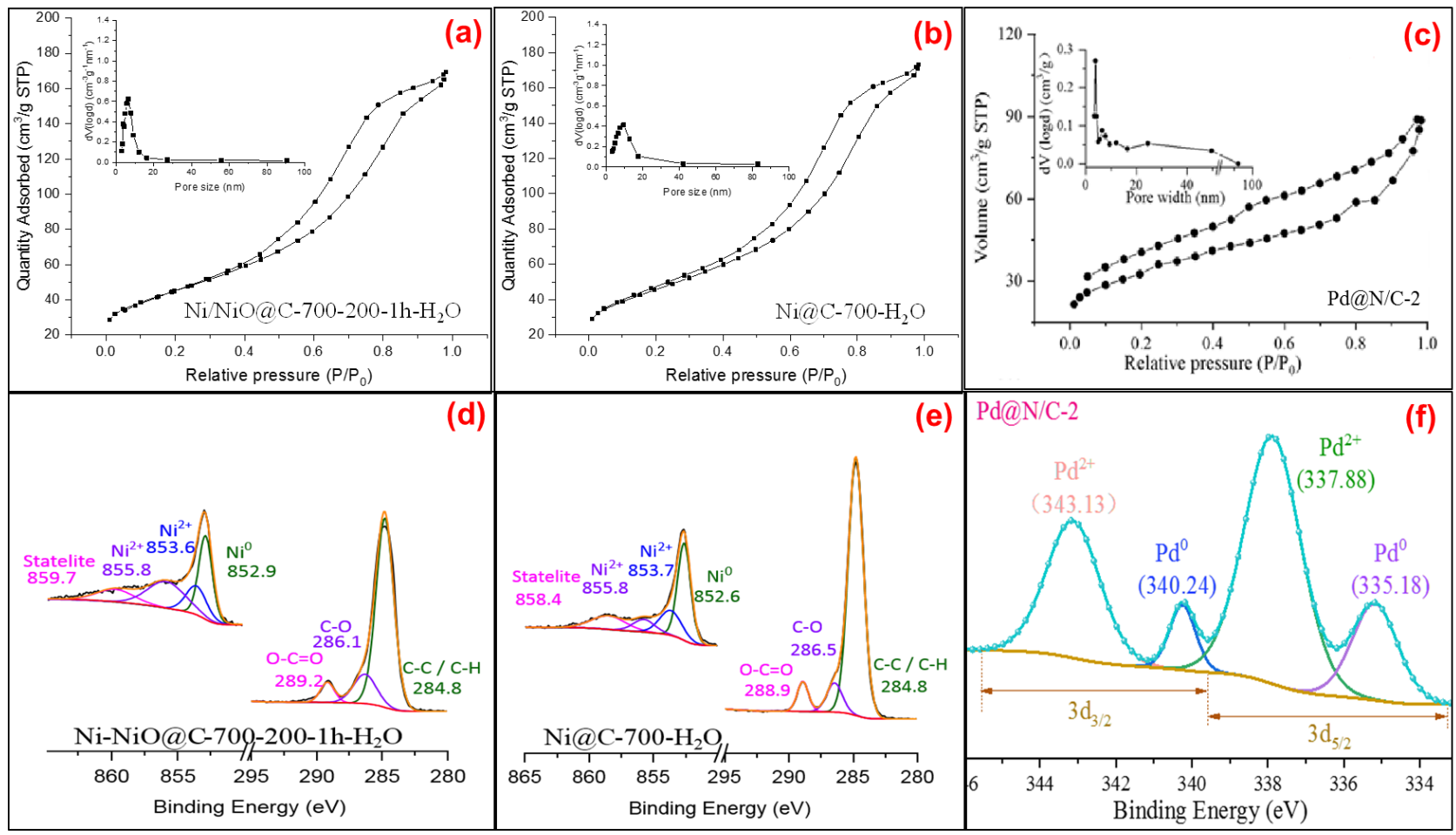

Figure 2. Representative BET measurements of $\mathrm{N}_{2}$ adsorption and desorption isotherm curves and pore size distribution profile of catalysts Ni@C-700-200-1h- $\mathrm{H}_{2} \mathrm{O}$ (a), Ni@C-700- $\mathrm{H}_{2} \mathrm{O}$ (b), Pd@NC-2 (c); Representative XPS images of Ni@C-700-200-1h- $\mathrm{H}_{2} \mathrm{O}$ (d), Ni@C-700- $\mathrm{H}_{2} \mathrm{O}(\mathbf{e}), \mathrm{Pd} @ \mathrm{NC}-2$ (f)

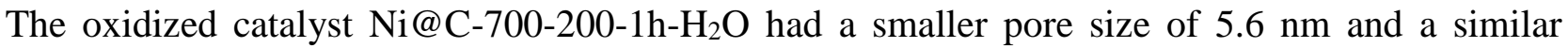
surface area of $160 \mathrm{~m}^{2} \mathrm{~g}^{-1}$ compared with the un-oxidized catalyst $\mathrm{Ni} @ \mathrm{C}-700-\mathrm{H}_{2} \mathrm{O}(6.5 \mathrm{~nm}, 162$ $\mathrm{m}^{2} \mathrm{~g}^{-1}$ ) (Table S1). When the pyrolysis temperature increased from $600{ }^{\circ} \mathrm{C}$ to $700{ }^{\circ} \mathrm{C}$, the pore size and surface area of the $\mathrm{Ni} @ \mathrm{C}-600-\mathrm{H}_{2} \mathrm{O}$ and $\mathrm{Ni} @ \mathrm{C}-700-\mathrm{H}_{2} \mathrm{O}$ catalysts both increased from 3.8 $\mathrm{nm}$ to $6.5 \mathrm{~nm}, 132 \mathrm{~m}^{2} \mathrm{~g}^{-1}$ to $162 \mathrm{~m}^{2} \mathrm{~g}^{-1}$ respectively (Table S1). Based on the X-ray photoelectron spectroscopy (XPS) (Figure 2d-f) analysis, both metallic $\mathrm{Ni}^{0}$ and $\mathrm{Ni}^{2+}$ species were presented on the catalyst's surface (Figure 2d, 2c). Also, for the N-doping catalyst Pd@ NC-2, the metallic $\mathrm{Pd}^{0}$ and $\mathrm{Pd}^{2+}$ species were observed. All of these observations indicated that the active metal species were easily oxidized during the preparation. The well-defined graphene shell encapsulated structure characteristics of the catalysts were confirmed by X-ray diffraction (XRD) measurement, as shown in Figure S2. All the prepared catalysts showed graphitic carbon shell C (002) between 20 and 30. Apart from the graphene shell $\mathrm{C}, \mathrm{Ni}$ alloy and $\mathrm{NiO}$ species were also present in the $\mathrm{Ni} @ \mathrm{C}$ catalysts (Figure S2). This indicated that the active metal Ni species of the $\mathrm{Ni} @ \mathrm{C}$ catalysts prepared from the non-oxidation step were also oxidized by air after the reduction process during storage. However, the observed increasing intensity peaks of $\mathrm{NiO}$ in the catalysts confirmed that 
more active metal species were oxidized during the oxidation process, which is consistent with the TEM statistical analysis (Table S1) and XPS analysis.

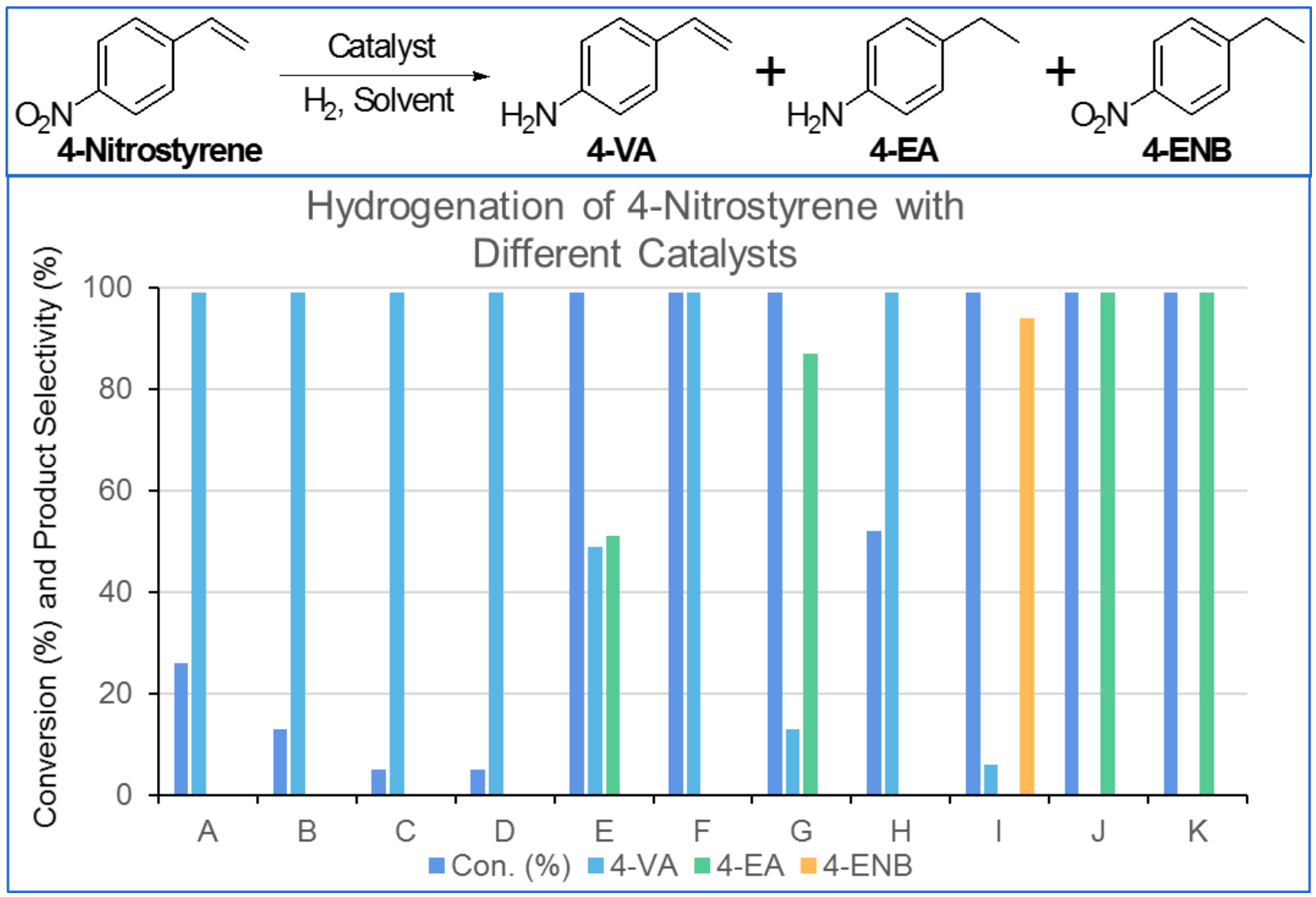

Figure 3. Catalyst Screening for the chemo selective hydrogenation of 4-nitrostyrene. Reaction conditions: $10 \mathrm{mg}$ catalyst, 0.5 mmol 4-nitrostyrene, 6 mL Toluene, 20 bar $\mathrm{H}_{2}, 1$ h, $120^{\circ} \mathrm{C}$. A: Ni@-600- $\mathrm{H}_{2} \mathrm{O}, \mathbf{B}: \mathrm{Ni} @-700-\mathrm{H}_{2} \mathrm{O}, \mathbf{C}: \mathrm{Ni} @-600-\mathrm{EtOH}, \mathbf{D}$ : $\mathrm{Ni} @-700-\mathrm{EtOH}, \quad \mathbf{E}: \quad \mathrm{Ni} / \mathrm{NiO} @-600-200-1-\mathrm{H}_{2} \mathrm{O}, \quad \mathbf{F}: \quad \mathrm{Ni} / \mathrm{NiO} @-700-200-1-\mathrm{H}_{2} \mathrm{O}, \quad \mathbf{J}: \quad \mathrm{Ni} / \mathrm{NiO} @-600-200-1-\mathrm{EtOH}, \quad \mathbf{H}:$ Ni/NiO@-700-200-2-EtOH, I: 5\% Ru/C, J: 5\% Pd/C, K: 5\% Pt/C. Conversion and selectivity were determined by GC using 1, 3, 5 -trimethoxybenzenen as an internal standard. The types of products were confirmed by GCMS and ${ }^{1} \mathrm{H}$ NMR

Here, we tested all the prepared $\mathrm{Ni@C}$ catalysts as well as the other commercially available catalysts $\mathrm{Ru} / \mathrm{C}, \mathrm{Pd} / \mathrm{C}$, and $\mathrm{Pt} / \mathrm{C}$ in the chemo-selective hydrogenation of 4-nitrostyrene under the $\mathrm{H}_{2}$ atmosphere. The distributions of the three products 4-VA, 4-EA, and 4-ENB over the different catalysts are shown in Figure 3. As mentioned previously, the oxidation step significantly affects the catalyst physical properties, here, it is clear see that the catalysts $\mathbf{E}, \mathbf{F}, \mathbf{J}, \mathbf{H}$ prepared with the oxidation step had higher conversion than the corresponding catalysts $\mathbf{A}, \mathbf{B}, \mathbf{C}, \mathbf{D}$ without the oxidation step. The solvent used for preparing the catalysts also affects the catalytic activity and product selectivity activity. The catalysts $\mathbf{A}, \mathbf{B}, \mathbf{E}, \mathbf{F}$ prepared from $\mathrm{H}_{2} \mathrm{O}$ generally had higher reactivity and 4-VA selectivity than the corresponding catalysts $\mathbf{C}, \mathbf{D}, \mathbf{J}, \mathbf{H}$ which were prepared from $\mathrm{EtOH}$. When the pyrolysis temperature increased from $600{ }^{\circ} \mathrm{C}$ to $700{ }^{\circ} \mathrm{C}$ for the catalysts in pairs of $\mathbf{A}$ and $\mathbf{B}, \mathbf{C}$ and $\mathbf{D}, \mathbf{E}$ and $\mathbf{F}, \mathbf{J}$ and $\mathbf{H}$, it is obvious to see the trend that the catalytic activity decreased respectively, no matter for the un-oxidized catalysts and oxidized catalysts. But for the 4-VA selectivity, all the un-oxidized catalysts in pairs of $\mathbf{A}$ and $\mathbf{B}, \mathbf{C}$ and $\mathbf{D}$, did not give any changes with all $99 \%$ of selectivity. For the oxidized catalysts in pairs of $\mathbf{E}$ and $\mathbf{F}, \mathbf{J}$ and $\mathbf{H}$, the product 4-VA selectivity increased when the pyrolysis temperature increased from $600{ }^{\circ} \mathrm{C}$ to 700 ${ }^{\circ} \mathrm{C}$. Among all the prepared thin graphene layer encapsulated Ni-based catalysts, the catalyst $\mathbf{F}$ $\mathrm{Ni} / \mathrm{NiO} @-700-200-1-\mathrm{H}_{2} \mathrm{O}$ showed the highest reactivity of $99 \%$, highest and excellent selectivity of 4-VA without observing 4-EA and 4-ENB. The other commercially available noble metal catalysts $\mathrm{Ru} / \mathrm{C}, \mathrm{Pd} / \mathrm{C}$, and $\mathrm{Pt} / \mathrm{C}$, which were usually applied in hydrogenation reaction due to their excellent hydrogenation ability, could also give excellent activity and selectivity of the other two products 4-EA and 4-ENB. Interestingly, the Ru/C gave the 4-ENB with $94 \%$ selectivity, while the $\mathrm{Pd} / \mathrm{C}$ and $\mathrm{Pt} / \mathrm{C}$ catalysts gave the fully over-hydrogenated product 4-EA with excellent selectivity. Here, it is a great need to mention some general conclusions. First, the prepared Ni catalyst has unique hydrogenation properties that are different from other noble metal catalysts $\mathrm{Ru} / \mathrm{C}, \mathrm{Pd} / \mathrm{C}$, 
Pt/C. Generally speaking, the Ni-based catalyst has been reported previously with similar hydrogenation properties like $\mathrm{Pd}, \mathrm{Pt}$, and $\mathrm{Ru} 18$ 69-71, however, in this chemo-selective hydrogenation 4-nitrostyrene that containing competing hydrogenation sensitive functional groups $-\mathrm{NO}_{2}$ and terminal olefin $\mathrm{C}=\mathrm{C}$ double bond, they showed different hydrogenation properties. In the non-polar, aprotic solvent toluene, the $\mathrm{Ni} @ \mathrm{C}$ catalyst preferred to hydrogenate the $-\mathrm{NO}_{2}$ functional group first without touching the usually more active terminal olefin $\mathrm{C}=\mathrm{C}$ double bond, however, the $\mathrm{Ru} / \mathrm{C}$ catalyst, instead, prefer first to hydrogenate the $\mathrm{C}=\mathrm{C}$ functional group. The highly active $\mathrm{Pd} / \mathrm{C}$ and $\mathrm{Pt} / \mathrm{C}$ are active and no-selective to both $-\mathrm{NO}_{2}$ and $\mathrm{C}=\mathrm{C}$ functional groups and can hydrogenate $\mathrm{C}=\mathrm{C}$ and $\mathrm{NO}_{2}$ functional groups at the same time, giving 4-EA the only product. Second, the solvent, pyrolysis temperature, and the oxidation step are crucial factors when preparing the graphene encapsulated $\mathrm{Ni} @ \mathrm{C}$ catalyst, which resulting in the dramatic difference in the chemo-selective hydrogenation of 4-nitrostyrene.

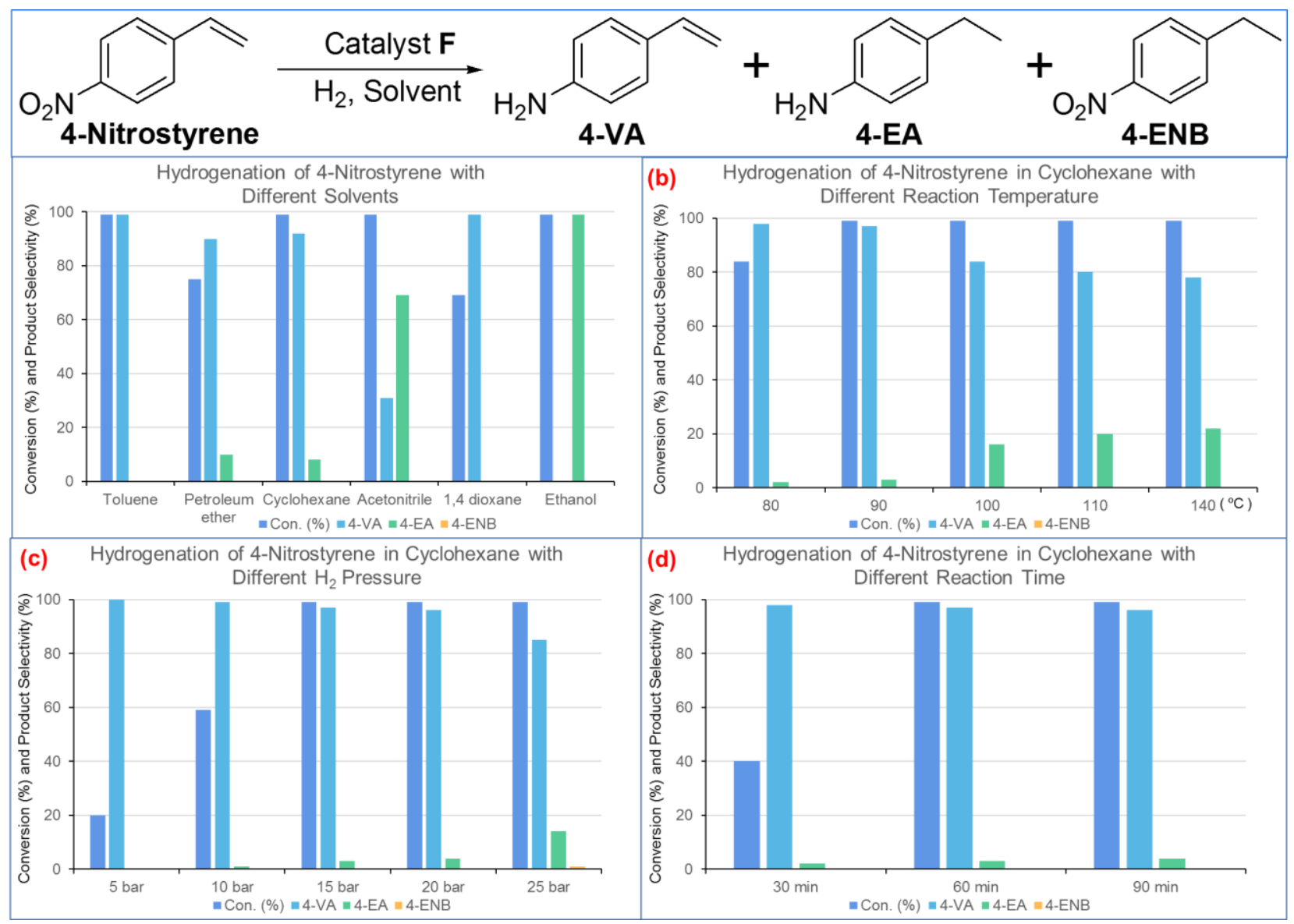

Figure 4. Study of reaction factors for the $\mathrm{Ni} @ \mathrm{C}$ catalyzed chemo selective hydrogenation of 4-nitrostyrene. Reaction conditions: (a) Reaction conditions: $10 \mathrm{mg}$ catalyst $\mathbf{F} \mathrm{Ni} / \mathrm{NiO} @-700-200-1-\mathrm{H}_{2} \mathrm{O}, 0.5 \mathrm{mmol}$ 4-nitrostyrene, $6 \mathrm{~mL}$ solvent, 20 bar $\mathrm{H}_{2}$, $1 \mathrm{~h}, 120{ }^{\circ} \mathrm{C}$; (b) Reaction conditions: $10 \mathrm{mg}$ catalyst $\mathbf{F} \mathrm{Ni} / \mathrm{NiO} @-700-200-1-\mathrm{H}_{2} \mathrm{O}, 0.5 \mathrm{mmol}$ 4-nitrostyrene, $6 \mathrm{~mL}$ cyclohexane, 20 bar $\mathrm{H}_{2}, 1 \mathrm{~h}$, different reaction temperature; (c) Reaction conditions: $10 \mathrm{mg}$ catalyst $\mathbf{F} \mathrm{Ni} / \mathrm{NiO} @-700-200-1-\mathrm{H}_{2} \mathrm{O}, 0.5 \mathrm{mmol}$ 4-nitrostyrene, $6 \mathrm{~mL}$ cyclohexane, different $\mathrm{H}_{2}$ pressure, $1 \mathrm{~h}, 90{ }^{\circ} \mathrm{C}$; (d) Reaction conditions: $10 \mathrm{mg}$ catalyst $\mathbf{F}$ $\mathrm{Ni} / \mathrm{NiO} @-700-200-1-\mathrm{H}_{2} \mathrm{O}, 0.5 \mathrm{mmol}$ 4-nitrostyrene, $6 \mathrm{~mL}$ cyclohexane, 15 bar $\mathrm{H}_{2}$, different reaction time, $90{ }^{\circ} \mathrm{C}$. Conversion and selectivity were determined by GC using 1,3,5-trimethoxybenzenen as an internal standard. The types of products were confirmed by GCMS and ${ }^{1} \mathrm{H}$ NMR

Based on the above initial catalysts' screening investigation, we further test reaction factors such as solvent, reaction temperature, hydrogen pressure, and reaction time using the optimized catalyst F. As shown in Figure 4a, the solvent had a great effect on the hydrogenation of 4-nitrostyrene under the optimized reaction conditions $\left(20\right.$ bar $\left.\mathrm{H}_{2}, 1 \mathrm{~h}, 120{ }^{\circ} \mathrm{C}\right)$. By changing from the solvent from no-polar, aprotic solvent toluene to the polar and protic solvent $\mathrm{EtOH}$, the catalytic reactivity and product selectivity changed dramatically. In the no-polar solvent toluene, petroleum ether, and cyclohexane, the selectivity of product 4-VA is higher than product 4-EA. While in the polar, protic solvent acetonitrile and EtOH, higher selectivity of 4-EA than 4-VA could be obtained. And using the graphene encapsulated no-noble Ni-based catalyst, we can both get the challenging product 4-VA with excellent selectivity of $99 \%$ and fully hydrogenated product 4-EA with super selectivity (>99\%) through changing the solvent simply, which could be a promising application in 
industry. Here, for the $\mathrm{Ni} @ \mathrm{C}$ catalyst, in the polar, protic solvent $\mathrm{EtOH}$, the hydrogenation rate of the $\mathrm{C}=\mathrm{C}$ double bond was increased dramatically compared with the non-polar, non-protic solvent cyclohexane, and the $\mathrm{NO}_{2}$ and $\mathrm{C}=\mathrm{C}$ double bond functional groups can be both hydrogenated completely. We also checked the reaction temperature, which is an important factor and costs a lot of energy during the industrial process. As illustrated in Figure $\mathbf{4 b}$, the hydrogenation conversion of 4-nitrostyrene increased significantly from $83 \%$ to $99 \%$ when the reaction temperature increased from $80{ }^{\circ} \mathrm{C}$ to $90{ }^{\circ} \mathrm{C}$, and then kept the full conversion at the reaction temperature of $100{ }^{\circ} \mathrm{C}, 110{ }^{\circ} \mathrm{C}$, and $140{ }^{\circ} \mathrm{C}$. The selectivity of 4-VA decreased slowly from $99 \%$ to $78 \%$ at $140{ }^{\circ} \mathrm{C}$, and 4-EA selectivity increased from $1 \%$ to $22 \%$ correspondingly, that is because some of 4-VA were further hydrogenated to 4-EA. This also indicated that, in the non-polar, aprotic solvent media cyclohexane, the hydrogenation rate of $\mathrm{NO}_{2}$ is fast than the double bond $\mathrm{C}=\mathrm{C}$. The $\mathrm{H}_{2}$ pressure, as another crucial factor that generally affects hydrogenation reaction significantly, was also evaluated in the chemo-selective hydrogenation of 4-nitrostyrene under $1 \mathrm{~h}, 90{ }^{\circ} \mathrm{C}$ conditions with varying different $\mathrm{H}_{2}$ pressures. As shown in Figure 4c, the conversion of 4-nitrostyrene increased in accordance with the $\mathrm{H}_{2}$ pressure increasing from 5 bar to 10 bar, 15 bar, 20 bar, and 25 bar gradually. And the selectivity of 4-VA gradually decreased from $100 \%$ to $85 \%$, since some of the 4-VA product were over-hydrogenated to 4-EA, which can be seen from the increasing yield of 4-EA. Here, it is interesting to see the phenomenon that the simultaneous hydrogenation of $\mathrm{C}=\mathrm{C}$ double bond and $\mathrm{NO}_{2}$ could also occur under the highest $\mathrm{H}_{2}$ pressure. Since not only the generally first step hydrogenated product 4-VA was observed in high yield, but also the over-hydrogenated product 4-EA could be obtained in high yield, and the other un-normally hydrogenated product 4-ENB could also be determined during the reaction. This indicated that, during the highest $\mathrm{H}_{2}$ pressure, the chemo-selective properties of the $\mathrm{Ni} @ \mathrm{C}$ began to non-distinguish the $\mathrm{C}=\mathrm{C}$ double bond and the $\mathrm{NO}_{2}$ functional group. Under this reaction condition, it can exceed the transition state energy barrier of the reaction pathways that produce three different products, therefore, three reaction routes can be followed to produce all three reaction products 4-VA, 4-EA, and 4-ENB. According to the kinetic hydrogenation of 4-nitrostyrene shown in Figure 4d, the hydrogenation rate of $\mathrm{NO}_{2}$ is very fast and can be finished in 60 minutes. With prolonging the reaction time, 4-VA began to further over-hydrogenate to 4-EA, and the selectivity of 4-VA decreased and 4-EA increased accordingly.

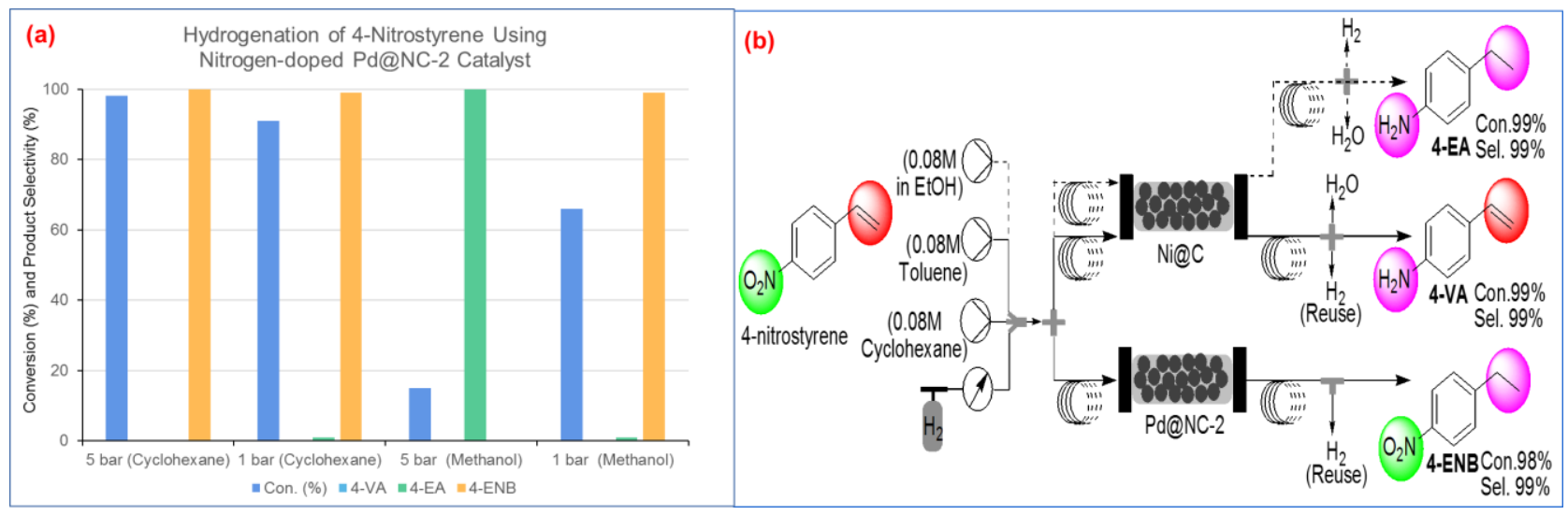

Figure 5. Study of reaction factors for the Pd@NC catalyzed chemo selective hydrogenation of 4-nitrostyrene and representative synthesis of three products in flow reactor. Reaction conditions: (a) Reaction conditions: $10 \mathrm{mg}$ catalyst Pd@NC-2, $0.5 \mathrm{mmol}$ 4-nitrostyrene, $6 \mathrm{~mL}$ solvent, 5 bar or 1 bar $\mathrm{H}_{2}, 1$ h, r.t.; (b) Reaction conditions: catalyst F $\mathrm{Ni} / \mathrm{NiO} @-700-200-1-\mathrm{H}_{2} \mathrm{O}, 4$-nitrostyrene $\left(0.08 \mathrm{M}\right.$ in EtOH), 20 bar $\mathrm{H}_{2}, 1 \mathrm{~h}, 120{ }^{\circ} \mathrm{C}$ (4-EA product synthesis); catalyst $\mathbf{F}$ $\mathrm{Ni} / \mathrm{NiO} @-700-200-1-\mathrm{H}_{2} \mathrm{O}$, 4-nitrostyrene (0.08 M in Cyclohexane), 20 bar $\mathrm{H}_{2}, 1 \mathrm{~h}, 120{ }^{\circ} \mathrm{C}$ (4-VA product synthesis); catalyst Pd@NC-2, 4-nitrostyrene (0.08 M in Cyclohexane), 5 bar $\mathrm{H}_{2}, 1$ h, r.t. (4-ENB product synthesis). Conversion and selectivity were determined by GC using 1, 3, 5-trimethoxybenzenen as an internal standard. The types of products were confirmed by GCMS and ${ }^{1} \mathrm{H}$ NMR

During the preparation of $\mathrm{Ni} @ \mathrm{C}$ catalysts, we also prepared the nitrogen-doped graphene encapsulated Pd@C with a similar modified synthesis method. Changing the Pd catalyst properties with nitrogen doping could affect its hydrogenation ability significantly ${ }^{72-74}$. As shown in the previously catalyst screening test Figure 3, the commercially available $\mathrm{Pd} / \mathrm{C}$ gave the fully hydrogenated product 4-EA. Herein, surprisingly, using the nitrogen-doped Pd@NC-2, excellent selectivity of 4-ENB was observed, which was not reported previously using the strong 
hydrogenation ability catalyst $\mathrm{Pd} / \mathrm{C}$ and $\mathrm{Pt} / \mathrm{C}$ (Figure 5a). As shown in Figure 3, an excellent yield of up to $94 \%$ 4-ENB could be obtained only when using the $\mathrm{Ru} / \mathrm{C}$ catalyst. Here, as illustrated in Figure 5a, the Pd@NC-2 catalyst was tested in the chemo-selective hydrogenation of 4-nitrostyrene in cyclohexane and $\mathrm{MeOH}$. When the reaction was carried out in cyclohexane, excellent reactivity of $98 \%$ conversion and super selectivity of 4-ENB up to $100 \%$ were obtained under the very mild reaction conditions (r.t., 5 bar $\mathrm{H}_{2}, 1$ hour). And during the other modified reaction conditions, the yield of the other two products 4-VA and 4-EA was lower than $2 \%$. It could conclude that in this reaction condition, unlike the above-mentioned graphene encapsulated $\mathrm{Ni} @ \mathrm{C}$ catalyst and other commercially available catalysts Pd/C and Pd/C, the Pd@ NC-2 catalyzed hydrogenation rate of double bond $\mathrm{C}=\mathrm{C}$ is faster than the hydrogenation rate of $\mathrm{NO}_{2}$ functional group. In the protic solvent $\mathrm{MeOH}$, when the $\mathrm{H}_{2}$ pressure decreased from 5 bar to 1 bar, the product selectivity of 4-ENB increased accordingly, which is a similar trend observed in cyclohexane. However, a lower conversion of $14 \%$ and only 4-EA could be obtained when the $\mathrm{H}_{2}$ pressure increased to 5 bar in solvent $\mathrm{MeOH}$. The catalyst's reusability and stability are important factors when concerning its application in industry. Both of the prepared graphene thin layers encapsulated Ni@C and Pd@NC catalysts showed excellent stability and reusability. Furthermore, it is also interesting to mention that the catalysts could be used in the advanced flow reactor and produce the three products 4-VA, 4-EA, and 4-ENB with super selectivity by simply varying the reaction conditions (Figure 5b). This opens a promising application in industrial using heterogeneous, sustainable, low-cost catalysts.

\section{CONCLUSION.}

In summary, we have developed highly efficient, chemo-selective thin layers graphene encapulcatulted $\mathrm{Ni} @ \mathrm{C}$ and Pd@C catalysts as new catalysts for active and selective hydrogenation of challenging 4-nitrostyrene to 4-vinylaniline, 4-ethylbenzenamine, and 1-ethyl-4-nitrobenzene separately. The solvent, pyrolysis temperature, and oxidation step had a great effect on the catalyst physical properties, catalytic activity, and product selectivity. The most efficient catalyst Ni/NiO@-700-200-1- $\mathrm{H}_{2} \mathrm{O}$ prepared from solvent $\mathrm{H}_{2} \mathrm{O}, 700{ }^{\circ} \mathrm{C}$ pyrolysis temperature, and oxidation step, could achieve $>99 \%$ 4-VA selectivity at $100 \%$ conversion of 4-nitrostyrene. The reaction conditions of solvent, reaction temperature, and $\mathrm{H}_{2}$ pressure affect the product distribution significantly. In non-polar solvent toluene, the $\mathrm{Ni} @ \mathrm{C}$ catalyst is more active for the $-\mathrm{NO}_{2}$ than $\mathrm{C}=\mathrm{C}$, but in the polar, protic solvent $\mathrm{EtOH}$, it can hydrogenate both $-\mathrm{NO}_{2}$ and $\mathrm{C}=\mathrm{C}$ groups. The prepared N-doped $\mathrm{Pd} @ \mathrm{C}$ has unique properties compared with commercially available $\mathrm{Pd} / \mathrm{C}$ and $\mathrm{Pt} / \mathrm{C}$, can only hydrogenate the $\mathrm{C}=\mathrm{C}$ without hydrogenating $\mathrm{NO}_{2}$, and give the 4-ENB an excellent yield of $99 \%$. And more interestingly, the active catalysts wearing graphene "bulletproof vests" have excellent stability and can be applied in advanced industrially applicable flow reactors for the three products synthesis separately with excellent yield by simple switching different control valves.

\section{ACKNOWLEDGMENT}

This work was supported financially by the National Key R\&D Program of China (2018YFB1501500), National Natural Science Foundation of China (51976225), DNL Cooperation Fund, and Chinese Academy of Sciences (DNL201916).

\section{AUTHOR CONTRIBUTIONS.}

J. G. L. and L. L. M supervised and designed the research. J.G.L, J.M.S. and S.S.L. performed the experiments and data analysis. J. G. L. wrote the original manuscript. All authors discussed the results and assisted during manuscript preparation.

\section{COMPETING INTERESTS.}

The authors declare no competing financial interests.

\section{DATA ABAILABILITY}

Data supporting the findings of this study are available from the corresponding authors upon 
reasonable request.

\section{ADDITIONAL INFORMATION.}

Correspondence and requests for materials should be addressed to J. G. L. or L. L. M.

\section{REFERENCES.}

1 Nishimura, S. Handbook of Heterogeneous Catalytic Hydrogenation for Organic Synthesis (Wiley-VCH, 2001).

2 Afanasyev, O. I., Kuchuk, E., Usanov, D. L. \& Chusov, D. Reductive Amination in the Synthesis of Pharmaceuticals. Chem. Rev. 119, 11857-11911 (2019).

3 Gunanathan, C., Ben-David, Y. \& Milstein, D. Direct synthesis of amides from alcohols and amines with liberation of $\mathrm{H}_{2}$. Science 317, 790-792 (2007).

4 Jagadeesh, R. V. et al. MOF-derived cobalt nanoparticles catalyze a general synthesis of amines. Science 358, 326-332 (2017).

5 Liu, J. et al. Facile synthesis of controllable graphene-co-shelled reusable $\mathrm{Ni} / \mathrm{NiO}$ nanoparticles and their application in the synthesis of amines under mild conditions. Green Chem. 22, 7387-7397, (2020).

6 Song, J. J. et al. Review on selective hydrogenation of nitroarene by catalytic, photocatalytic and electrocatalytic reactions. Appl. Catal. B-Environ. 227, 386-408 (2018).

7 Njarðarson, J. Top 200 Brand Name Drugs by Retail Sales in 2020, <https://njardarson.lab.arizona.edu/sites/njardarson.lab.arizona.edu/files/Top\%20200\%20Pharmaceuticals\%20B y\%20Retail\%20Sales\%202020V3.pdf> (2021).

8 Zhou, F. et al. Clinical course and risk factors for mortality of adult inpatients with COVID-19 in Wuhan, China: a retrospective cohort study. Lancet 395, 1054-1062 (2020).

9 Mehta, P. et al. COVID-19: consider cytokine storm syndromes and immunosuppression. Lancet 395, 1033-1034 (2020).

10 Wu, Z. \& McGoogan, J. M. Characteristics of and Important Lessons From the Coronavirus Disease 2019 (COVID-19) Outbreak in China Summary of a Report of 72314 Cases From the Chinese Center for Disease Control and Prevention. Jama-J. Am. Med. Assoc. 323, 1239-1242, (2020).

11 Kinjo, R., Donnadieu, B., Celik, M. A., Frenking, G. \& Bertrand, G. Synthesis and Characterization of a Neutral Tricoordinate Organoboron Isoelectronic with Amines. Science 333, 610-613 (2011).

12 Silverio, D. L. et al. Simple organic molecules as catalysts for enantioselective synthesis of amines and alcohols. Nature 494, 216-221 (2013).

13 Pavlidis, I. V. et al. Identification of (S)-selective transaminases for the asymmetric synthesis of bulky chiral amines. Nat. Chem. 8, 1076-1082 (2016).

14 Hahn, G., Kunnas, P., de Jonge, N. \& Kempe, R. General synthesis of primary amines via reductive amination employing a reusable nickel catalyst. Nat. Catal. 2, 71-77 (2019).

15 Yasukawa, T., Masuda, R. \& Kobayashi, S. Development of heterogeneous catalyst systems for the continuous synthesis of chiral amines via asymmetric hydrogenation. Nat. Catal. 2, 1088-1092, (2019).

16 Corma, A. \& Serna, P. Chemoselective hydrogenation of nitro compounds with supported gold catalysts. Science 313, 332-334 (2006).

17 Beier, M. J., Andanson, J. M. \& Baiker, A. Tuning the Chemoselective Hydrogenation of Nitrostyrenes Catalyzed by Ionic Liquid-Supported Platinum Nanoparticles. ACS Catal. 2, 2587-2595 (2012).

18 Makosch, M. et al. Organic Thiol Modified $\mathrm{Pt} / \mathrm{TiO}_{2}$ Catalysts to Control Chemoselective Hydrogenation of Substituted Nitroarenes. ACS Catal. 2, 2079-2081 (2012).

19 Furukawa, S., Yoshida, Y. \& Komatsu, T. Chemoselective Hydrogenation of Nitrostyrene to Aminostyrene over Pd- and Rh-Based Intermetallic Compounds. ACS Catal. 4, 1441-1450 (2014).

20 Tan, Y. et al. ZnAl-Hydrotalcite-Supported Au-25 Nanoclusters as Precatalysts for Chemoselective Hydrogenation of 3-Nitrostyrene. Angew. Chem. Int. Ed. 56, 2709-2713 (2017). 
21 Zhang, L. L., Zhou, M. X., Wang, A. Q. \& Zhang, T. Selective Hydrogenation over Supported Metal Catalysts: From Nanoparticles to Single Atoms. Chem. Rev. 120, 683-733 (2020).

22 Yarulin, A. et al. Pt-Zn nanoparticles supported on porous polymeric matrix for selective 3-nitrostyrene hydrogenation. J. Catal. 321, 7-12 (2015).

23 Furukawa, S., Takahashi, K. \& Komatsu, T. Well-structured bimetallic surface capable of molecular recognition for chemoselective nitroarene hydrogenation. Chem. Sci. 7, 4476-4484 (2016).

24 Hamm, G. et al. The Adsorption of Ethene on Pd(111) and Ordered Sn/Pd(111) Surface Alloys. Z Phys Chem 223, 209-232 (2009).

$25 \mathrm{Li}$, J. et al. Robust Synthesis of Gold-Based Multishell Structures as Plasmonic Catalysts for Selective Hydrogenation of 4-Nitrostyrene. Angew. Chem. Int. Ed. 59, 1103-1107, (2020).

26 F. Kovar, F. E. A. U.S. patent (1976).

27 Basu, M. K., Becker, F. F. \& Banik, B. K. Ultrasound-promoted highly efficient reduction of aromatic nitro compounds to the aromatic amines by samarium/ammonium chloride. Tetrahedron Lett. 41, 5603-5606 (2000).

28 Bellamy, F. D. \& Ou, K. Selective Reduction of Aromatic Nitro-Compounds with Stannous Chloride in Non-Acidic and Non-Aqueous Medium. Tetrahedron Lett. 25, 839-842 (1984).

29 Wei, H. S. et al. FeOx-supported platinum single-atom and pseudo-single-atom catalysts for chemoselective hydrogenation of functionalized nitroarenes. Nat. Commun. 5 (2014).

30 Tan, Y. et al. ZnAl-Hydrotalcite-Supported Au-25 Nanoclusters as Precatalysts for Chemoselective Hydrogenation of 3-Nitrostyrene. Angew. Chem. Int. Ed. 56, 2709-2713 (2017).

31 Macino, M. et al. Tuning of catalytic sites in $\mathrm{Pt} / \mathrm{TiO}_{2}$ catalysts for the chemoselective hydrogenation of 3-nitrostyrene. Nat. Catal. 2, 873-881 (2019).

32 Liu, J., Song, Y. \& Ma, L. Earth-abundant Metal-catalyzed Reductive Amination: Recent Advances and Prospect for Future Catalysis. Chem. Asian J. (2021).

33 Boddien, A. et al. Efficient Dehydrogenation of Formic Acid Using an Iron Catalyst. Science 333, 1733-1736 (2011).

34 Tondreau, A. M. et al. Iron Catalysts for Selective Anti-Markovnikov Alkene Hydrosilylation Using Tertiary Silanes. Science 335, 567-570 (2012).

35 Zuo, W. W., Lough, A. J., Li, Y. F. \& Morris, R. H. Amine(imine)diphosphine Iron Catalysts for Asymmetric Transfer Hydrogenation of Ketones and Imines. Science 342, 1080-1083 (2013).

36 Friedfeld, M. R. et al. Cobalt Precursors for High-Throughput Discovery of Base Metal Asymmetric Alkene Hydrogenation Catalysts. Science 342, 1076-1080 (2013).

37 Jagadeesh, R. V. et al. Nanoscale $\mathrm{Fe}_{2} \mathrm{O}_{3}$-Based Catalysts for Selective Hydrogenation of Nitroarenes to Anilines. Science 342, 1073-1076 (2013).

38 Yu, R. P., Hesk, D., Rivera, N., Pelczer, I. \& Chirik, P. J. Iron-catalysed tritiation of pharmaceuticals. Nature 529, 195-199 (2016).

39 Hughes, M. D. et al. Tunable gold catalysts for selective hydrocarbon oxidation under mild conditions. Nature 437, 1132-1135 (2005).

40 Galvis, H. M. T. et al. Supported Iron Nanoparticles as Catalysts for Sustainable Production of Lower Olefins. Science 335, 835-838 (2012).

41 Sankar, M. et al. Designing bimetallic catalysts for a green and sustainable future. Chem. Soc. Rev. 41, 8099-8139 (2012).

42 van Schrojenstein Lantman, E. M., Deckert-Gaudig, T., Mank, A. J. G., Deckert, V. \& Weckhuysen, B. M. Catalytic processes monitored at the nanoscale with tip-enhanced Raman spectroscopy. Nat. Nanotechnol. 7, 583-586 (2012).

43 Prieto, G., Zecevic, J., Friedrich, H., de Jong, K. P. \& de Jongh, P. E. Towards stable catalysts by controlling collective properties of supported metal nanoparticles. Nat. Mater. 12, 34-39 (2013).

44 Luo, W. H. et al. High performing and stable supported nano-alloys for the catalytic hydrogenation of levulinic acid to gamma-valerolactone. Nat. Commun. 6 (2015). 
45 Munnik, P., de Jongh, P. E. \& de Jong, K. P. Recent Developments in the Synthesis of Supported Catalysts. Chem. Rev. 115, 6687-6718 (2015).

46 Zecevic, J., Vanbutsele, G., de Jong, K. P. \& Martens, J. A. Nanoscale intimacy in bifunctional catalysts for selective conversion of hydrocarbons. Nature 528, 245-248 (2015).

47 Friedfeld, M. R., Zhong, H. Y., Ruck, R. T., Shevlin, M. \& Chirik, P. J. Cobalt-catalyzed asymmetric hydrogenation of enamides enabled by single-electron reduction. Science 360, 888-892 (2018).

48 Qin, Z. Z., Liu, Z. L. \& Wang, Y. H. Promotion Effect of Mo in Amorphous Ni-P Catalysts for the Liquid-Phase Catalytic Hydrogenation of Nitrobenzene to Aniline. Chem. Eng. Commun. 201, 338-351 (2014).

49 Reddy, P. L., Tripathi, M., Arundhathi, R. \& Rawat, D. S. Chemoselective Hydrazine-mediated Transfer Hydrogenation of Nitroarenes by $\mathrm{Co}_{3} \mathrm{O}_{4}$ Nanoparticles Immobilized on an Al/Si-mixed Oxide Support. Chem. Asian J. 12, 785-791 (2017).

50 Yang, F. et al. Atomically dispersed $\mathrm{Ni}$ as the active site towards selective hydrogenation of nitroarenes. Green Chem. 21, 704-711 (2019).

51 Cao, Y. L., Liu, K. K., Wu, C., Zhang, H. P. \& Zhang, Q. Y. In situ-formed cobalt embedded into N-doped carbon as highly efficient and selective catalysts for the hydrogenation of halogenated nitrobenzenes under mild conditions. Appl. Catal. A-Gen. 592 (2020).

52 Fronczak, M., Kasprzak, A. \& Bystrzejewski, M. Carbon-encapsulated iron nanoparticles with deposited Pd: A high-performance catalyst for hydrogenation of nitro compounds. J. Environ. Chem. Eng. 9, 3 (2021).

53 Tian, S. B. et al. Single-atom $\mathrm{Fe}$ with $\mathrm{Fe}_{1} \mathrm{~N}_{3}$ structure showing superior performances for both hydrogenation and transfer hydrogenation of nitrobenzene. Sci. China. Mater. 64, 642-650 (2021).

54 Westerhaus, F. A. et al. Heterogenized cobalt oxide catalysts for nitroarene reduction by pyrolysis of molecularly defined complexes. Nat. Chem. 5, 537-543 (2013).

55 Liu, L. C., Concepcion, P. \& Corma, A. Non-noble metal catalysts for hydrogenation: A facile method for preparing Co nanoparticles covered with thin layered carbon. J. Catal. 340, 1-9 (2016).

56 Sorribes, I., Liu, L. C. \& Corma, A. Nanolayered Co-Mo-S Catalysts for the Chemoselective Hydrogenation of Nitroarenes. ACS Catal. 7, 2698-2708 (2017).

57 Corma, A., Serna, P., Concepcion, P. \& Calvino, J. J. Transforming nonselective into chemoselective metal catalysts for the hydrogenation of substituted nitroaromatics. J. Am. Chem. Soc. 130, 8748-8753 (2008).

58 Shen, M. Q. et al. Room-Temperature Chemoselective Reduction of 3-Nitrostyrene to 3-Vinylaniline by Ammonia Borane over Cu Nanoparticles. J. Am. Chem. Soc. 140, 16460-16463 (2018).

59 Kolmer, M. et al. Rational synthesis of atomically precise graphene nanoribbons directly on metal oxide surfaces. Science 369, 571-575 (2020).

60 Geim, A. K. \& Novoselov, K. S. The rise of graphene. Nat. Mater. 6, 183-191 (2007).

61 Geim, A. K. Graphene: Status and Prospects. Science 324, 1530-1534 (2009).

62 Castro Neto, A. H., Guinea, F., Peres, N. M. R., Novoselov, K. S. \& Geim, A. K. The electronic properties of graphene. Rev. Mod. Phys. 81, 109-162 (2009).

63 Wong, D. L. et al. Cascade of electronic transitions in magic-angle twisted bilayer graphene. Nature 582, 198-202 (2020).

64 Cao, Y. et al. Tunable correlated states and spin-polarized phases in twisted bilayer-bilayer graphene. Nature 583, 215-220 (2020).

65 Park, J. M., Cao, Y., Watanabe, K., Taniguchi, T. \& Jarillo-Herrero, P. Tunable strongly coupled superconductivity in magic-angle twisted trilayer graphene. Nature 590, 249-255 (2021).

66 Deng, J., Ren, P. J., Deng, D. H. \& Bao, X. H. Enhanced Electron Penetration through an Ultrathin Graphene Layer for Highly Efficient Catalysis of the Hydrogen Evolution Reaction. Angew. Chem. Int. Ed. 54, 2100-2104 (2015).

67 Bunch, J. S. et al. Impermeable atomic membranes from graphene sheets. Nano Lett. 8, 2458-2462 (2008).

68 Qiu, L., Liu, J. Z., Chang, S. L. Y., Wu, Y. Z. \& Li, D. Biomimetic superelastic graphene-based cellular monoliths. Nat. Commun. 3 (2012). 
69 Blaser, H. U., Steiner, H. \& Studer, M. Selective Catalytic Hydrogenation of Functionalized Nitroarenes: An Update. Chemcatchem 1, 210-221 (2009).

70 Liu, L. C. \& Corma, A. Metal Catalysts for Heterogeneous Catalysis: From Single Atoms to Nanoclusters and Nanoparticles. Chem. Rev. 118, $4981-5079$ (2018).

71 Wang, A. Q., Li, J. \& Zhang, T. Heterogeneous single-atom catalysis. Nat. Rev. Chem. 2, 65-81 (2018).

72 Arrigo, R. et al. Nature of the N-Pd Interaction in Nitrogen-Doped Carbon Nanotube Catalysts. ACS Catal. 5, 2740-2753 (2015).

73 Nie, R. F., Jiang, H. Z., Lu, X. H., Zhou, D. \& Xia, Q. H. Highly active electron-deficient Pd clusters on N-doped active carbon for aromatic ring hydrogenation. Catal. Sci. Technol. 6, 1913-1920 (2016).

$74 \mathrm{Nie}, \mathrm{R}$. F. et al. Selective hydrogenation of $\mathrm{C}=\mathrm{C}$ bond over N-doped reduced graphene oxides supported $\mathrm{Pd}$ catalyst. Appl. Catal. B-Environ. 180, 607-613 (2016). 